Original Research Article

\title{
Pharmacoeconomic analysis of drug expenditure in government medical college and hospital, Vijayawada, India
}

\author{
Y. Bala Suresh Kumar Reddy*, Sankar K.
}

Department of pharmacology, Siddhartha Medical College, Vijayawada, Andhra Pradesh, India

Received: 30 January 2018 Accepted: 06 March 2018

\section{*Correspondence to:}

Dr. Y. Bala Suresh Kumar Reddy,

Email: y.balasuresh@gmail.com

Copyright: (C) the author(s), publisher and licensee Medip Academy. This is an openaccess article distributed under the terms of the Creative Commons Attribution NonCommercial License, which permits unrestricted noncommercial use, distribution, and reproduction in any medium, provided the original work is properly cited.

\begin{abstract}
Background: To conduct economic analysis in tertiary care hospital with a view to identify the categories of drugs needing stringent management control.

Methods: The annual consumption and expenditure data is obtained from the drug store of government general hospital, Vijayawada, for the period of April 2015 to March 2016. ABC-VED analysis of the drugs are done based on cost and criticality criteria respectively. ABC-VED matrix analysis was done to classify drugs into category I, II, III.

Results: The total annual drug expenditure incurred on 299 drug items for the year 2015-2016 was found to be Rs:4,47,04,446. On ABC analysis, 4\%, 9.36\%, $86.64 \%$ of drugs were found to be Always, Better, and Control category items respectively, amounting to $68.92 \%, 20.05 \%, 11.03 \%$ of annual drug expenditure. VED analysis showed that $32.10 \%, 45.5 \%, 22.4 \%$ of drug items were Vital, Essential, and Desirable category items respectively, amounting to $35.3 \%, 37.1 \%$, $27.6 \%$ of annual drug expenditure respectively. By ABC-VED matrix analysis, $34.11 \%, 46.49 \%, 19.4 \%$ of drug items were found to be category I (high stringent), II (medium stringent), III (low stringent) respectively, amounting to $80.76 \%, 17.46 \%, 1.77 \%$ of annual drug expenditure respectively.

Conclusions: The study identified $34.11 \%$ of drug items belonging to category I which require high priority monitoring. Inventory management tools must be routinely used for the better control and judicious use of the resources.
\end{abstract}

Keywords: $\mathrm{ABC}$ analysis, $\mathrm{ABC}-\mathrm{VED}$ matrix, Inventory management, Pharmacy, VED analysis

\section{INTRODUCTION}

The modern system of medicine has transformed into a more complex, effective, sophisticated and expensive treatment modality in terms of cost of medicines, consumables and equipment. About one-third of the annual hospital budget is spent on buying materials and supplies, out of which drugs consume the most. ${ }^{1}$ The medical stores along with the dispensary where distribution of medicines takes place is one of the important part in the health care system with respect to the amount of money spent, health care delivery, and the overall satisfaction of hospital clientele. Hence, this signifies the need for planning, designing and organizing the pharmacy in a manner that results in efficient clinical and administrative services. ${ }^{2}$

Of the various explanations for non-availability of even simple medicines in the third world countries, a large number were found to be related to materials management. ${ }^{3}$ A study conducted by Pillans et al, In a 1500-bedded state-funded hospital has claimed that better inventory control technique brought about $20 \%$ savings in hospital expenditure. ${ }^{4}$ Multiple published studies have shown that inventory control techniques when made a routine practice in healthcare could bring about substantial improvement in patient care as well as optimal use of 
resources. ${ }^{5,6}$ As resources are limited, it is essential that the existing resources be appropriately utilized.

Inventory control is a scientific system which indicates as to what to order, when to order, and how much to order, and how much to stock so that purchasing costs and storing costs are kept as low as possible. It helps to protect against the fluctuation in supply and demand, uncertainty and minimise waiting time.

Out of various inventory control techniques available, $\mathrm{ABC}$ analysis, and VED analysis are most suitable and commonly used techniques in medical stores due to their dependence upon cost and criticality of drugs respectively.

$\mathrm{ABC}$ analysis is a method of classifying items or activities according to their monetary importance. It is popularly known as "Always Better Control". It is based on Pareto's principal of "separating the vital few from the trivial many". The analysis classifies the items into three categories: the first $10-15 \%$ of the items account for approximately $70 \%$ of cumulative value (cost) (category A), 20-25\% are category B items that account for a further $20 \%$ of the cumulative value and the remaining $65-70 \%$ are category $\mathrm{C}$ items, amounting for a mere $10 \%$ of the total value (Table 1).

Table 1: ABC Analysis.

\begin{tabular}{|lll|}
\hline Item & Drugs (\%) & Budget/ capital value (\%) \\
\hline A & 10 & 70 \\
\hline B & 20 & 20 \\
\hline C & 70 & 10 \\
\hline
\end{tabular}

VED analysis is based on critical values and shortage cost of the item. Based on their criticality, the items could be classified into three categories: vital, essential and desirable. There could be serious functional dislocation of patient care services in hospital when vital drugs are not available even for a short period. If essential items are not available beyond a few days or a week, the functioning of the hospital can be adversely affected. The shortage of desirable items would not adversely affect patient care or hospital functioning even if shortage is prolonged., 8

ABC-VED Matrix analysis takes both the above analysis into consideration and gives results based on economic as well as critical value of drugs simultaneously. It also classifies drugs into categories according to the priority of their control.

In this study, $A B C$, VED and ABC-VED matrix analysis of the pharmacy store of Government General Hospital, Vijayawada, A.P, was performed to identify the categories of drugs needing stringent management control and the specific objectives of this study were to:

- Analyse the annual consumption of items of pharmacy and expenditure incurred on them for the year 2015-16.
- $\quad$ evolve a priority system based on ABC and VED and ABC-VED matrix analysis.

- Identify the item categories requiring greater supervisory monitoring.

\section{METHODS}

The study was an observational study carried out in the pharmacy store of Government General Hospital, Vijayawada, A.P for a period of one month.

The data for annual consumption and expenditure incurred on each drug of the drug store, for the financial year 20152016 was collected and fed into MS Excel spread sheet. The statistical analysis was carried out using the MS Excel statistical functions. Annual usage for each drug (Consumption $\times$ Cost) was calculated separately from the data retrieved. The annual drug expenditure (ADE) was calculated for the financial year 2015-2016 by adding the expenditure incurred on each item. The drug indent for the financial year 2015-2016 consisted of 299 drugs and the annual drug expenditure (ADE) for the financial year 2015-2016 was Rs: 4,47,04,446.

\section{ABC analysis}

The annual expenditure of individual items was arranged in descending order. The cumulative percentage of expenditure and the cumulative percentage of number of items were calculated. This list was then subdivided into three categories: A, B and C, based on the cumulative cost percentage of $70 \%, 20 \%$ and $10 \%$, respectively.

\section{VED analysis}

The VED analysis for all the listed drug items was performed by classifying the items into vital (V), essential (E) and desirable (D) categories keeping the standard definitions in consideration.

\section{Vitals}

Items critically needed for the survival of patients and those that must be available at all times in the hospital, as their non-availability can seriously affect the image of the hospital.

\section{Essential}

Items with low criticality need and whose shortage may be tolerated for short period in the hospital.

\section{Desirable}

Item with lowest criticality, shortage of which would not be detrimental to health of patients. ${ }^{10}$ 
The VED status of each drug item was discussed with justification by the department of pharmacology faculty members.

\section{$A B C-V E D$ matrix analysis}

The ABC-VED matrix was formulated by cross-tabulating the ABC and VED analysis. From the resultant combination, three categories were classified (I, II and III). Category I was constituted by items belonging to AV, AE, $\mathrm{AD}, \mathrm{BV}$ and $\mathrm{CV}$ subcategories. The $\mathrm{BE}, \mathrm{CE}$ and $\mathrm{BD}$ subcategories constituted category II, and the remaining items in the CD subcategory constituted category III. In these subcategories, the first alphabet denotes its place in the $\mathrm{ABC}$ analysis, while the second alphabet stands for its place in the VED analysis (Table 2).

Table 2: ABC-VED matrix.

\begin{tabular}{|llll|}
\hline & V & E & D \\
\hline A & AV & AE & AD \\
\hline B & BV & BE & BD \\
\hline C & CV & CE & CD \\
\hline
\end{tabular}

\section{RESULTS}

The drug indent for the financial year 2015-2016 consisted of 299 drugs. The annual drug expenditure (ADE) for the financial year 2015-2016 was Rs:4,47,04,446.

Table 3: ABC analyses of drugs.

\begin{tabular}{|llll|l|}
\hline Category & $\begin{array}{l}\text { No. of } \\
\text { drugs }\end{array}$ & $\begin{array}{l}\text { \% of } \\
\text { drugs }\end{array}$ & ADE (Rs.) & $\begin{array}{c}\text { \% of } \\
\text { ADE }\end{array}$ \\
\hline A & 12 & 4 & $3,08,10,380$ & 68.92 \\
\hline B & 28 & 9.36 & $89,63,734$ & 20.05 \\
\hline C & 259 & 86.64 & $49,30,332$ & 11.03 \\
\hline Total & 299 & 100 & 44704446 & 100 \\
\hline
\end{tabular}

\section{ABC analysis}

On ABC analysis, 4\% (12), 9.36\% (28), 86.64\% (259) of drugs were found to be Always, Better, and Control category items respectively, amounting to $68.92 \%$ (Rs. 3,08,10,380), 20.05\% (Rs. 89,63,734), 11.03\% (Rs. $49,30,332)$ of annual drug expenditure of the pharmacy (Table 3). The cut-offs were not exactly at 70/20/10\% and differed marginally, which is permissible.

\section{VED analysis}

The VED analysis of the study are shown in Table 4. About 32.1\% (96), 45.5\% (136) and 22.4\% (67) items were found to be V, E and D category items, respectively, amounting for $35.3 \%$ (Rs. 1,57,68,457), 37.1\% (Rs. $1,66,06,316$ ) and $27.6 \%$ (Rs. $1,23,29,673$ ) of ADE of the pharmacy.

Table 4: VED analyses of drugs.

\begin{tabular}{|lllll|}
\hline Category & $\begin{array}{l}\text { No. of } \\
\text { drugs }\end{array}$ & $\begin{array}{l}\text { \% of } \\
\text { drugs }\end{array}$ & ADE (Rs.) & $\begin{array}{l}\text { \% of } \\
\text { ADE }\end{array}$ \\
\hline V & 96 & 32.1 & $1,57,68,457$ & 35.3 \\
\hline E & 136 & 45.5 & $1,66,06,316$ & 37.1 \\
\hline D & 67 & 22.4 & $1,23,29,673$ & 27.6 \\
\hline Total & 299 & 100 & $4,47,04,446$ & 100 \\
\hline
\end{tabular}

\section{$A B C-V E D$ matrix analysis}

Table 5, Table 6 shows the ABC-VED matrix analysis. Nine different subcategories (AV, AE, AD, BV, BE, BD, $\mathrm{CV}, \mathrm{CE}$ and $\mathrm{CD}$ ) were studied using this analysis. These nine were further grouped into three main categories, categories I, II and III.

\section{Table 5: ABC-VED matrix of drugs.}

\begin{tabular}{|lllll|}
\hline Category & $\begin{array}{l}\text { No. of } \\
\text { drugs }\end{array}$ & $\begin{array}{l}\% \text { of } \\
\text { drugs }\end{array}$ & ADE (Rs.) & $\begin{array}{l}\% \text { of } \\
\text { ADE }\end{array}$ \\
\hline I & 102 & 34.11 & $3,61,05,337$ & 80.76 \\
\hline II & 139 & 46.49 & $78,06,132$ & 17.46 \\
\hline III & 58 & 19.4 & $7,92,977$ & 1.77 \\
\hline Total & 299 & 100 & $4,47,04,446$ & 100 \\
\hline
\end{tabular}

Table 6: ABC-VED Matrix.

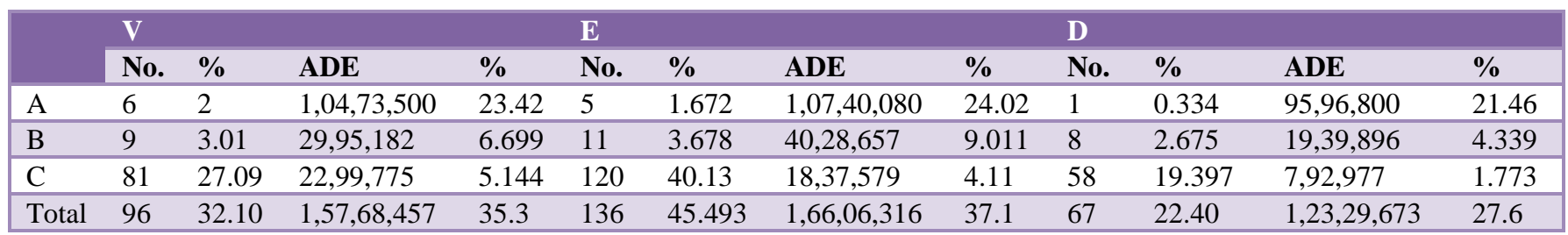

\section{DISCUSSION}

In the present healthcare environment of "limited resource and unlimited demand", no healthcare organization will have abundant resources and hence, optimal utilization of existing resources for contributing towards maximum benefit of hospital clientele will be an essential component of hospital logistics management. Future healthcare 
managers will have to utilize scientific methods of inventory management and the role of an efficient hospital logistics system cannot be ignored anymore. ${ }^{11}$

The regular availability of the necessary medicines is the topmost priority for any hospital. Each hospital has to evolve its own drug inventory analysis system depending on the population and the health care problems it caters. To avoid stock-outs as well as excess stocks, cost and criticality of the drugs are two important factors which have to be taken into account in drug inventory analysis. ${ }^{12}$

ABC analysis of the drug store of government general hospital, Vijayawada, south India, revealed that out of 299 drug items considered for the study, only $4.01 \%$ (12) drugs consumed $69 \%$ of the total drug expenditure. And $9.36 \%$ (28) drugs consumed $20.05 \%$ of the total drug expenditure and the remaining $11.03 \%$ of the expenditure covers the entire drugs list. Considering $\mathrm{ABC}$ analysis alone, will enable us to ensure adequate control over $89 \%$ of the budget with stringent control over just 40 drug items.

But, ABC analysis alone provides a managerial tool for selectively controlling inventory on annual usage value alone, neglecting the criticality factor which is not acceptable in medical practice, and hence, VED analysis and $\mathrm{ABC}-\mathrm{VED}$ matrix tools are also employed.

VED analysis of our drug store revealed that out of 299 items considered for study, 32.10\% (96) drug items were vital and $45.5 \%$ (136) drug items were essential and $22.4 \%$ (67) drug items are desirable.

In a combination of $\mathrm{ABC}$ and VED analysis, the resultant matrix makes it possible to focus on 102 (34.11\%) items belonging to category I for strict managerial control as these items are either expensive or vital. The annual expenditure of these items was $80.76 \%$ of $\mathrm{ADE}$ of the pharmacy.
$\mathrm{AV}, \mathrm{AE}$ and BV subgroups of category I consist of 20 items $(6.69 \%)$ that are expensive, and their being out of stock is unacceptable as they are either vital or essential.

To prevent locking up of capital due to these items, low buffer stock needs to be maintained while keeping a strict vigil on the consumption level and the stock in hand. A two-bin method of ordering needs to be followed for these as this will eliminate the risk of item shortage.

CV items $(81,27.09 \%)$ are drugs of low cost but high criticality and take up $5.144 \%$ of ADE of the pharmacy. Because this amount is negligible, these items can be procured once a year and stocked as their carrying cost is low.

AD items (only one [factor VIII], $0.33 \%$ ) consume $21.46 \%$ of the ADE. This item should be monitored for economic order quality, and its order placement must be made after careful study of the need. Rational use of this item, including its removal from the general list if possible, or allocating a different budget, can bring about substantial savings without affecting patient care. And since this hospital is a haemophilia patient care centre, it is very much advisable to allocate a different budget for this item.

Category II items $(139,46.49 \%)$ consumes $17.46 \%$ of the ADE. These items can be ordered once or twice a year, thereby saving on ordering cost and reducing management hassles at a moderate carrying cost and without blocking substantial capital. Category III items (58, 19.4\%) consume $1.77 \%$ of the ADE. These items can also be ordered once or twice a year, thereby saving on ordering cost at a moderate carrying cost and without blocking substantial capital.

The comparison with similar studies in India is shown in Table 7.

Table 7: Comparison of various $\mathrm{ABC}, \mathrm{VED}$ and $\mathrm{ABC}-\mathrm{VED}$ matrix results.

\begin{tabular}{|c|c|c|c|c|c|c|}
\hline Category & Gupta et al ${ }^{10}$ & Junita et al ${ }^{13}$ & Khurana et al ${ }^{12}$ & Devnani et $a^{5}$ & Sandeep et al $^{13}$ & Present study \\
\hline A & 14.6 & 7.74 & 3.45 & 13.78 & 16.8 & 4.01 \\
\hline B & 22.4 & 11.01 & 6.9 & 21.85 & 21.8 & 9.36 \\
\hline $\mathrm{C}$ & 63 & 81.25 & 89.65 & 64.37 & 61.4 & 86.63 \\
\hline V & 7.4 & 6.6 & 32.41 & 12.11 & 35.3 & 32.10 \\
\hline $\mathrm{E}$ & 49.2 & 33.6 & 61.38 & 59.38 & 50.4 & 45.5 \\
\hline $\mathrm{D}$ & 43.4 & 59.8 & 6.2 & 28.51 & 14.3 & 22.4 \\
\hline I & 20.9 & 11.9 & 33.8 & 22.09 & 47.9 & 34.11 \\
\hline II & 48.9 & 37.8 & 60 & 54.63 & 43.7 & 17.46 \\
\hline III & 30.2 & 50.3 & 6.2 & 23.28 & 8.4 & 1.77 \\
\hline
\end{tabular}

All the values are the \% values of the drug items in each category

The study suffers from the limitation of being a single hospital study and thus the study findings cannot be generalized for all service hospitals. And the differences in the $\%$ values of drug items in various categories are mostly due to the differences in the locality, kinds of cases and patients, and the differences in uses of the drugs. However, 
the concept of selective inventory control is universal for achieving the aim of "Right drug in right quantity at right price and at right place".

\section{CONCLUSION}

During the year 2015-16, items of approximately Rs. $4,47,04,446$ were issued by the pharmacy store of GGH, Vijayawada. This necessitates the regular application of scientific inventory management tools for effective and efficient management of the pharmacy stores, efficient priority setting, decision making in purchase and distribution of specific items and close supervision on items belonging to important categories.

\section{ACKNOWLEDGEMENTS}

Authors would like to acknowledge Government General Hospital pharmacy, Vijayawada, A.P.

Funding: No funding sources

Conflict of interest: None declared

Ethical approval: Not required

\section{REFERENCES}

1. Kant S, Pandaw CS, Nath LM. A management technique for effective management of medical store in hospitals. Medical store management technique. J Acad Hosp Adm. 1996;8-9:41-7.

2. Kunders GD, Gopinath S, Katakam A. In: Hospitals: Planning, Design and Management. New Delhi: Tata McGraw-Hill Publishing Company Limited; Planning and designing supportive services-Pharmacy; 2000:273-281.

3. Kidwai M. National Institute of Health and Family Welfare; New Delhi: Inaugural Address. Logistics and Supply Management for Health and Family Planning Programme: A Report of Inter-country Course; 1992:66-70.

4. Pillans PI, Conry I, Gie BE. Drug cost containment at a large teaching hospital. Pharmacoeconomics. 1992;1:377-82. [PubMed]
5. Devnani M, Gupta A, Nigah R. ABC and VED analysis of the pharmacy store of a tertiary care teaching, research and referral healthcare institute of India. J Young Pharm. 2010;2:201-5. [PubMed]

6. Thawani VR, Turanker AV, Sontakke SD. Economic analysis of drug expenditure at Government Medical College Hospital, Nagpur. Indian J Pharmacol. 2004;36:15-9.

7. Nursing Management. ABC, VED, HML analysis in material management. Available at: http://www.currentnursing.com/nursing_management /material_management_ABC_VED_HML_analysis. [Last updated $2011 \mathrm{Feb}$ 17, Last cited 2011 May 24].

8. Das JK. Inventory Control. In: Kaushik M, Agarwal AK, Arora SB, editors. Essentials of Logistics and Equipment Management, Manual of Post Graduate Diploma in Hospital and Health Management. New Delhi: Indira Gandhi National Open University, School of Health Sciences; 2001.

9. Vaz FS, Ferreira AM, Kulkarni MS, Motghare DD, Pereira-Antao I. A Study of Drug Expenditure at a Tertiary Care Hospital: An ABC-VED Analysis. J Health Manag. 2008;10:119-27.

10. Gupta R, Gupta KK, Jain BR, Garg RK. ABC and VED Analysis in Medical Stores Inventory; MJAFI. 2007;63:325-7.

11. Gupta S, Kant S. Hospital Stores Management - An Integral Approach. Jaypee Brothers Medical Publishers(P) Ltd; New Delhi: Inventory control; 2000:60-72.

12. Khurana S, Chhillar N, Gautam VKS. Inventory control techniques in medical stores of a tertiary care neuropsychiatry hospital in Delhi. Health. 2013;5(1):8-13.

13. Junita I, Sari RK. ABC-VED Analysis and Economic Order Interval (EOI) -Multiple Items for Medicines Inventory Control in Hospital. 2012:678-89.

Cite this article as: Reddy YBSK, Sankar K. Pharmacoeconomic analysis of drug expenditure in government medical college and hospital, Vijayawada, India. Int J Basic Clin Pharmacol 2018;7:873-7. 